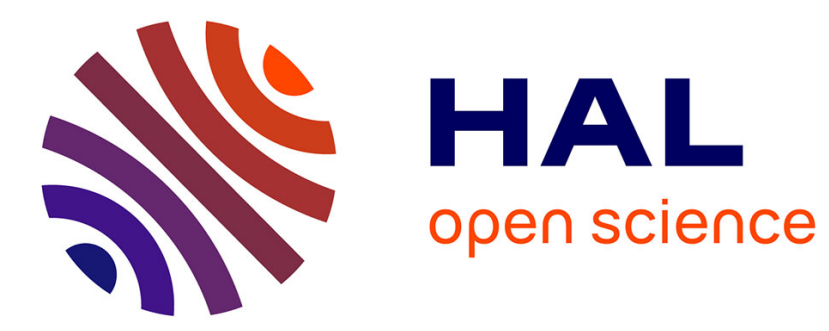

\title{
FIRST-ORDER ANTIFERROMAGNETIC TRANSITION IN CUBIC TbAg
}

P Morin, J. Rouchy, M. Amado, R. Pinto, J. Moreira, V. Amaral, M. Braga, J. Sousa

\section{- To cite this version:}

P Morin, J. Rouchy, M. Amado, R. Pinto, J. Moreira, et al.. FIRST-ORDER ANTIFERROMAGNETIC TRANSITION IN CUBIC TbAg. Journal de Physique Colloques, 1988, 49 (C8), pp.C8-395C8-396. 10.1051/jphyscol:19888179 . jpa-00228332

\section{HAL Id: jpa-00228332 https://hal.science/jpa-00228332}

Submitted on 1 Jan 1988

HAL is a multi-disciplinary open access archive for the deposit and dissemination of scientific research documents, whether they are published or not. The documents may come from teaching and research institutions in France or abroad, or from public or private research centers.
L'archive ouverte pluridisciplinaire HAL, est destinée au dépôt et à la diffusion de documents scientifiques de niveau recherche, publiés ou non, émanant des établissements d'enseignement et de recherche français ou étrangers, des laboratoires publics ou privés. 


\title{
FIRST-ORDER ANTIFERROMAGNETIC TRANSITION IN CUBIC TbAg
}

\author{
P. Morin $\left({ }^{1}\right)$, J. Rouchy $\left({ }^{1}\right)$, M. M. Amado $\left({ }^{2}\right)$, R. P. Pinto $\left({ }^{2}\right)$, J. M. Moreira $\left({ }^{2}\right)$, V. S. Amaral $\left({ }^{2}\right)$, \\ M. E. Braga $\left({ }^{2}\right)$ and J. B. Sousa $\left({ }^{2}\right)$ \\ (1) Laboratoire Louis Néel, C.N.R.S., 166X, 38042 Grenoble Cedex, France \\ ${ }^{2}$ Centro de Fisica da Universidade, Porto, INIC, 4000 Porto, Portugal
}

\begin{abstract}
Experimental results from magnetization, D.T.A. and transport properties give, for the first time, clear evidence on the first-order nature of the antiferromagnetic transition in cubic TbAg single crystals. Several physical mechanisms are briefly considered.
\end{abstract}

\section{Introduction}

First-order magnetic transitions are rather frequent in rare earth intermetallic compounds with non magnetic alloyed metals [1]. They have been often explained as driven by quadrupolar interactions in particular in CsCl-type compounds. Additional couplings, such as two-ion magnetoelasticity, or fluctuations may also be of some importance for a correct minimization of the free energy [2]. Usually, these first-order transitions occur at rather low temperature (say for instance below $30 \mathrm{~K}$ in $\mathrm{CeZn}$ [3]. Among rare earth-silver compounds, $\mathrm{TbAg}$ lies in a peculiar position. Indeed its Néel temperature does not follow the De Gennes law valid across heavy rare earth compounds (Tab. I) and a first-order transition may be suspected. This is supported by the possibility of important quadrupolar interactions associated with the large second-order Stevens coefficient for Tb. Here we present measurements for the magnetization and transport properties.

Table I. - Néel temperature observed and expected from a De Gennes law based on the GdAg value.

\begin{tabular}{|c|c|c|c|c|c|c|}
\hline $\mathrm{RAg}$ & $\mathrm{Gd}$ & $\mathrm{Tb}$ & $\mathrm{Dy}$ & $\mathrm{Ho}$ & $\mathrm{Er}$ & $\mathrm{Tm}$ \\
\hline $\begin{array}{c}\text { observed } \\
T_{\mathrm{N}}(\mathrm{K}) \\
\text { expected }\end{array}$ & 128 & $\begin{array}{c}103.5 \\
8\end{array}$ & 54 & 33 & 17 & 9.5 \\
\hline
\end{tabular}

\section{Magnetic measurements}

According to the Landau theory, the magnetization may be expanded as a function of the (applied or exchange) field:

$$
M(T, H)=\chi(T) H+\chi^{(3)}(T) H^{3}+\ldots
$$

Independently of the microscopic origin of the thirdorder susceptibility $\chi^{(3)}$, its sign at $T_{N}$ determines the nature of the transition: for $\chi^{(3)}$ positive (negative), the transition is first (second) order. The $\chi$ and $\chi^{(3)}$ susceptibilities (Fig. 1) were deduced from isothermal magnetization curves in the paramagnetic state under magnetic fields up to $70 \mathrm{kOe}$ applied along the [001] easy magnetization axis. The inverse susceptibility $\left(\chi^{-1}\right)$ is strictly linear in temperature down to about $130 \mathrm{~K}$, at which a small upwards curvature appears. A sudden step-like increase $(\sim 10 \%)$ is observed defining $T_{\mathrm{N}}=103.5 \mathrm{~K}$. In the ordered state, $\chi^{-1}$ increases strongly in decreasing $T$ down to $40 \mathrm{~K}$; below $40 \mathrm{~K}, \chi^{-1}$ decreases again. The magnitude of $\chi^{(3)}$ is very small due to the negative ferromagnetic interactions. It is about ten times smaller than $\mathrm{PrPb}_{3}$, previously studied [4] and already close to the experimental resolution. Clearly, $\chi^{(3)}$ is negative, but quickly rises towards positive values in the vicinity of the transition. The observed behaviour for $\chi$ and $\chi^{(3)}$ is then consistent with a first-order antiferromagnetic transi-

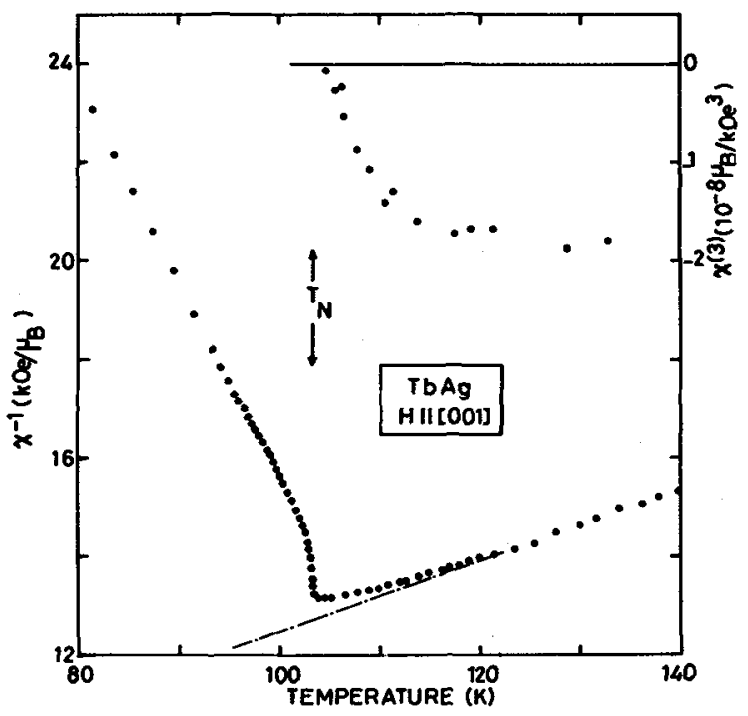

Fig. 1. - Reciprocal first-order magnetic susceptibility (left scale), third-order magnetic susceptibility (right scale) according to the temperature in TbAg for a magnetic field along [001].

\footnotetext{
${ }^{1}$ Work supported by C.N.R.S.-INICT Grant, INIC and Ambassade de France.
} 
tion. We have to keep in mind that the rapid variation of $\chi^{(3)}$ near $T_{\mathrm{N}}$ may be not fully compatible with a quadrupolar susceptibility alone which would maintain a slower temperature dependence. This may be the signature of additional couplings or fluctuations as previously observed in RSb pnictides [2].

\section{Transport properties}

The electrical resistivity $(\rho)$, measured in decreasing temperatures, shows a sharp drop at $T_{\mathrm{N}}$, corresponding to a discontinuity $\Delta \rho / \rho \sim 5.5 \%$. The thermal conductivity $(K)$ shows a similar discontinuity, but in the opposite sense, $\Delta K / K=-6 \%$ (Fig. 2a). The opposite signs are consistent with the qualitative expectancies from a Wiedemann-Franz-type dependence, for which the electronic thermal conductivity varies with the inverse of the electrical resistivity. Direct measurements of the temperature derivative of $\rho, \mathrm{d} \rho / \mathrm{d} T$, show an extremely narrow positive peak at $T_{\mathrm{N}}$ (Fig. $2 \mathrm{~b}$ ) in a characteristic manner for first-order transitions. A discontinuity was also observed in the thermopower and its temperature derivative. A D.T.A. scan through the transition led to a very sharp peak. A full analysis of these results will be presented elsewhere.

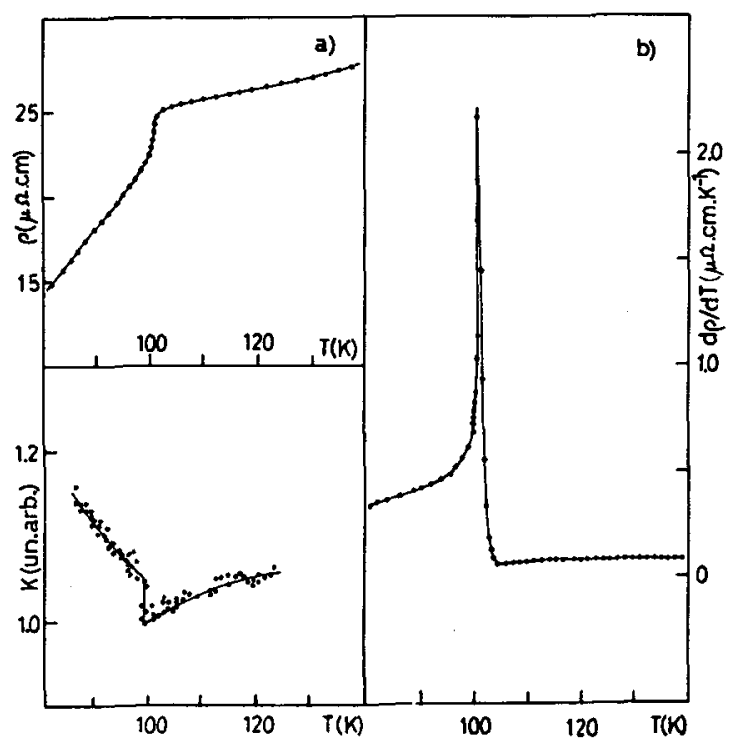

Fig. 2. - Temperature variation of the electric resistivity (a), its derivative (b) and of the thermal conductivity in the range of the Néel temperature in $\mathrm{TbAg}$.
The first-order nature of the antiferromagnetic ordering in $\mathrm{TbAg}$ is then well-established. The ratio between experimental and theoretical Néel temperatures is about 1.2 (Tab. 1). As in other CsCl-type compounds [1], the first-order character may be driven by tetragonal symmetry quadrupolar interactions. Indeed, from the analysis of elastic constants in the paramagnetic phase [5], the quadrupolar interactions are positive and seem to be strong enough to drive the $\chi^{(3)}$ susceptibility to be positive and the transition first-order.

The magnetization jump is rather small when the tricritical point $T_{c}^{*}$, at which $\chi^{(3)}$ changes sign occurs at high temperatures, where both the third-order susceptibility and its temperature dependence become weak. These latter facts make the tricritical temperature strongly dependent on the actual value of the quadrupolar interactions, but also on other possible couplings. For instance the role of metallurgicallyoriginated stresses has been well established for the rare earth silver series: this may determine, at least partly, the magnetic structure as observed in $\mathrm{Ho}^{-}$, Er- and TmAg $[6,7]$ and the strain domain structure in the quadrupolar phase of CeAg [8]. In addition, magnetic fluctuations and/or two-ion magnetoelasticity may precipitate the spin system to order [2]. In TbAg, they appear to weakly manifest themselves in both the magnetization and transport properties. From preliminary results, they seem to be of the same order of magnitude as in $\mathrm{GdAg}$, which undergoes a second-order antiferromagnetic ordering. Therefore, they do not appear as a deciding factor for the firstorder transition, but perhaps for the actual value at which $T_{\mathrm{N}}$ occurs.

[1] Morin, P. and Schmitt, D., Phys. Rev. B 27 (1983) 4412;

Koetzler, J., Z. Phys. B 55 (1984) 119.

[2] Aléonard, R., Morin, P., Schmitt, D. and Hulliger, F., J. Phys. F 14 (1984) 2689.

[3] Pierre, J., Murani, A. P. and Galera, R. M., J. Phys. F 11 (1981) 679.

[4] Morin, P., Schmitt, D. and Du Trémolet de Lacheisserie, E., J. Magn. Magn. Mater. 30 (1982) 257.

[5] Aléonard, R., Morin, P. and Rouchy, J. (this conference).

[6] Nereson, N., A.I.P. Conf. Proc. 10 (1973) 669.

[7] Morin, P. and Schmitt, D., J. Magn. Magn. Mater. 28 (1982) 188.

[8] Morin, P., J. Magn. Magn. Mater. 71 (1988) 151. 